OPEN ACCESS

Edited by:

Deyan Ge,

Chinese Academy of Sciences

(CAS), China

Reviewed by:

Xiao-Guang Qi,

Northwest University, China

Xuming Zhou,

Chinese Academy of Sciences

(CAS), China

*Correspondence:

Li Yu

yuli@ynu.edu.cn

Specialty section:

This article was submitted to

Evolutionary and Population Genetics,

a section of the journal

Frontiers in Genetics

Received: 10 October 2020 Accepted: 17 November 2020 Published: 15 December 2020

Citation:

Kuang W, Hu J, Wu H, Fen X, Dai Q,

$F u$ Q, Xiao W, Frantz L, Roos C

Nadler T, Irwin DM, Zhou L, Yang $X$

and Yu L (2020) Genetic Diversity, Inbreeding Level, and Genetic Load in

Endangered Snub-Nosed Monkeys

(Rhinopithecus).

Front. Genet. 11:615926.

doi: 10.3389/fgene.2020.615926

\section{Genetic Diversity, Inbreeding Level, and Genetic Load in Endangered Snub-Nosed Monkeys (Rhinopithecus)}

\author{
Weimin Kuang ${ }^{1}$, Jingyang $\mathrm{Hu}^{1}$, Hong $\mathrm{Wu}^{1}{ }^{1}$, Xiaotian Fen ${ }^{2,3,4}$, Qingyan $\mathrm{Dai}^{2,3,4}$, \\ Qiaomei Fu ${ }^{2,3,4}$, Wen Xiao ${ }^{5}$, Laurent Frantz ${ }^{6,7}$, Christian Roos ${ }^{8}$, Tilo Nadler ${ }^{9}$, \\ David M. Irwin ${ }^{10}$, Linchun Zhou ${ }^{11}$, Xu Yang ${ }^{12}$ and Li Yu ${ }^{1 *}$
}

${ }^{1}$ State Key Laboratory for Conservation and Utilization of Bio-Resource in Yunnan, School of Life Sciences, Yunnan University, Kunming, China, ${ }^{2}$ Key Laboratory of Vertebrate Evolution and Human Origins of Chinese Academy of Sciences, IVPP, CAS, Beijing, China, ${ }^{3}$ Center for Excellence in Life and Paleoenvironment, Chinese Academy of Sciences, Beijing, China, ${ }^{4}$ Beijing College of Life Science, University of Chinese Academy of Sciences, Beijing, China, ${ }^{5}$ Institute of Eastern-Himalaya Biodiversity Research, Dali University, Dali, China, ${ }^{6}$ School of Biological and Chemical Sciences, Queen Mary University of London, London, United Kingdom, ${ }^{7}$ The Palaeogenomics and Bio-Archaeology Research Network, Department of Archaeology, University of Oxford, Oxford, United Kingdom, ${ }^{8}$ Gene Bank of Primates and Primate Genetics Laboratory, German Primate Center, Leibniz Institute for Primate Research, Göttingen, Germany, ${ }^{9}$ Wildlife Consultant, Ninh Binh, Vietnam, ${ }^{10}$ Department of Laboratory Medicine and Pathobiology, University of Toronto, Toronto, ON, Canada, ${ }^{11}$ Lushui Management and Conservation Branch of Gaoligong Mountain National Nature Reserve, Nujiang, China, ${ }^{12}$ Lushui Forestry and Grassland Council, Nujiang, China

The snub-nosed monkey genus (Rhinopithecus) comprises five closely related species (R. avunculus, $R$. bieti, $R$. brelichi, $R$. roxellana, and $R$. strykeri). All are among the world's rarest and most endangered primates. However, the genomic impact associated with their population decline remains unknown. We analyzed population genomic data of all five snub-nosed monkey species to assess their genetic diversity, inbreeding level, and genetic load. For $R$. roxellana, $R$. bieti, and $R$. strykeri, population size is positively correlated with genetic diversity and negatively correlated with levels of inbreeding. Other species, however, which possess small population sizes, such as $R$. brelichi and $R$. avunculus, show high levels of genetic diversity and low levels of genomic inbreeding. Similarly, in the three populations of $R$. roxellana, the Shennongjia population, which possesses the lowest population size, displays a higher level of genetic diversity and lower level of genomic inbreeding. These findings suggest that although $R$. brelichi and $R$. avunculus and the Shennongjia population might be at risk, it possess significant genetic diversity and could thus help strengthen their long-term survival potential. Intriguingly, $R$. roxellana with large population size possess high genetic diversity and low level of genetic load, but they show the highest recent inbreeding level compared with the other snub-nosed monkeys. This suggests that, despite its large population size, $R$. roxellana has likely been experiencing recent inbreeding, which has not yet affected its mutational load and fitness. Analyses of homozygous-derived deleterious mutations identified in all snub-nosed monkey species indicate that these mutations are affecting immune, especially in smaller population sizes, indicating that the long-term consequences of inbreeding may be resulting in an overall reduction of immune capability in the snub-nosed monkeys, which could provide a dramatic effect 
on their long-term survival prospects. Altogether, our study provides valuable information concerning the genomic impact of population decline of the snub-nosed monkeys. We revealed multiple counterintuitive and unexpected patterns of genetic diversity in small and large population, which will be essential for conservation management of these endangered species.

Keywords: snub-nosed monkeys, population genomics, genetic diversity, inbreeding, genetic load, population decline

\section{INTRODUCTION}

The snub-nosed monkey genus (Rhinopithecus) comprises five closely related species. The golden snub-nosed monkey ( $R$. roxellana), Yunnan snub-nosed monkey ( $R$. bieti), and Guizhou snub-nosed monkey ( $R$. brelichi) are endemic to China, while the Tonkin snub-nosed monkey ( $R$. avunculus) is distributed in northern Vietnam, and the Myanmar/Nujiang snub-nosed monkey (R. strykeri) inhabits northern Myanmar and the Nujiang prefecture in China (Geissmann et al., 2011; Liedigk et al., 2012; Ma et al., 2014; Meyer et al., 2017) (Figure 1). Currently, all five species are classified as endangered or critically endangered on the International Union for Conservation of Nature (IUCN) Red List.

Fossil records indicate that the snub-nosed monkeys were widely distributed across East Asia during the Late Pleistocene and Early Holocene (Han, 1982; Jablonski and Pan, 1988; Jablonski, 1998). Environmental changes during the Holocene, however, led to habitat loss and fragmentation for all five species, and this process was likely accelerated by increasing human activities over the last 400 years (Li et al., 2002; Nuchel et al., 2018). In fact, recent field surveys indicated that the population sizes in these species were extremely low. For example, there are only 22,500 individuals of $R$. roxellana, the most numerous species, which are isolated in three fragmented populations in the Minshan and Qionglai mountains (SG; Sichuan/Gansu provinces), the Qinling mountain (QL; Shanxi province), and the Shennongjia National Nature Reserve (SNJ; Hubei province) (Quan and Xie, 2002; Liu et al., 2015; Li et al., 2018). Other species, such as $R$. bieti and R. strykeri are only $\sim 3,000$ (Li et al., 2018; Zhao et al., 2019) and 950 individuals (Meyer et al., 2017; Ren et al., 2017; Yang et al., 2019), respectively, and there are fewer than 400 and 200 individuals of most endangered species R. brelichi (Guo et al., 2020) and R. avunculus (Nadler, 2018) left in the wild, respectively.

These dramatically low population sizes, if maintained long enough, may cause loss of genetic diversity, increase of inbreeding, and accumulation of deleterious mutations (genetic load), all of which can reduce adaptive potential and dramatically increase risk of extinction (Hansson and Westerberg, 2002; Frankham, 2005; Heller and Zavaleta, 2009; Jump et al., 2009). These issues, however, can be mitigated with appropriate conservation management that takes into account genetic diversity (Frankham, 2005). Yet, despite the fact that many studies have investigated the taxonomy, phylogeography, and deep evolutionary history of the snub-nosed monkeys based on mitochondrial DNA and microsatellites (Zhang and Ryder, 1997;
Li et al., 2004, 2007; Liu et al., 2007, 2009, 2015; Chang et al., 2012; Liedigk et al., 2012; Yang et al., 2012; Kolleck et al., 2013; Hong et al., 2017), and more recently based on whole genome sequencing (Zhou et al., 2014, 2016; Yu et al., 2016; Kuang et al., 2019), little is known about the genetic diversity and levels of inbreeding in these populations.

To explore the genetic diversity, inbreeding level, and genetic load in these species, we analyzed 62 genome sequences representing individuals from all five snub-nosed monkeys. Our study provides valuable information concerning the genomic impact of population decline of the snub-nosed monkeys. In particular, we unravel unexpected patterns of genetic diversity in small and large population, which will be essential for conservation management of these endangered species.

\section{MATERIALS AND METHODS}

\section{Data Collection and Genome Sequencing}

Ninety-five published genomic data from all five snub-nosed monkeys, including $57 R$. roxellana, $28 R$. bieti, $1 R$. avunculus, 5 R. brelichi, and 4 R. strykeri (Zhou et al., 2014, 2016; Yu et al., 2016; Kuang et al., 2019) were downloaded from the National Center for Biotechnology Information (NCBI). An additional, seven $R$. bieti, three $R$. strykeri, and one $R$. avunculus were sequenced in this study (Supplementary Table 1). A bone (R.strykeri-7) and two skin (R.strykeri-5 and R.strykeri-6) samples of R. strykeri individuals from the Gaoligong Mountain National Nature Reserve were provided by the Nujiang Forest Public Security Bureau and the Institute of Eastern-Himalaya Biodiversity Research, respectively. A skin (R.avunculus-2) sample of R. avunculus from the Ba Be National Park of northern Vietnam was provided by the Gene Bank of Primates at the German Primate Center. DNA samples of $R$. bieti from the Baima Mountain National Nature Reserve were provided by the Animal Branch of the Germplasm Bank of wild Species of Chinese Academy of Science. With the addition of these new samples, we obtained a total of 106 population genomes (average 12.02-fold coverage) representing all five snub-nosed monkeys. The genomic sequences from Pygathrix nemaeus (red shanked douc langur) and Macaca mulatta (rhesus macaque; SRS748669; Zhang et al., 2014) were used as outgroups. The DNA sample of Pygathrix nemaeus obtained from the Animal Branch of the Germplasm Bank of wild Species of Chinese Academy of Science was used to generate the genomic sequences (32.13fold coverage). 


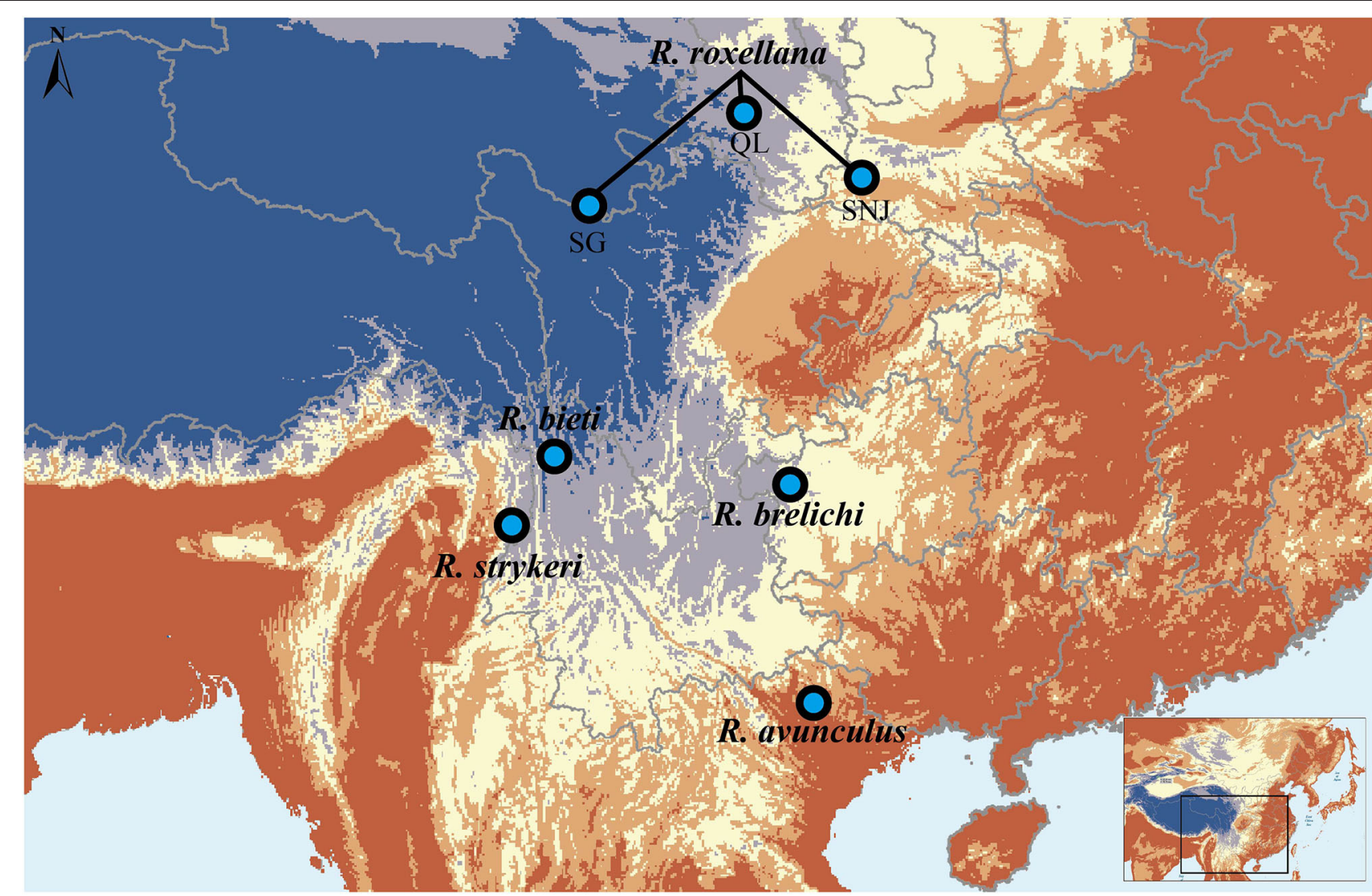

FIGURE 1 | Geographic distribution of the Rhinopithecus species. The map is drawn using ESRI ArcGIS 10.2.

Genomic DNAs from the skin and bone samples of $R$. strykeri and $R$. avunculus were extracted in the ancient DNA extraction facility of the Institute of Vertebrate Paleontology and Paleoanthropology (IVPP), Chinese Academy of Sciences, Beijing, China (for details, see Supplementary Notes). Sequencing libraries were produced using a double stranded library preparation protocol (Meyer and Kircher, 2010; Kircher et al., 2012) with uracil-DNA-glycosylase (UDG) and endonuclease (Endo VIII) treated (for details see Supplementary Notes). Sequencing libraries were sequenced using paired-end (PE) 150-bp reads on an Illumina HiSeq $\mathrm{X}$-ten platform. Reads were demultiplexed by allowing one mismatch on each pair of reads. A modified version of SeqPrep (John, 2011) were used to collapse the PE reads (at least 11-bp overlap with one mismatch allowed), and base quality in the overlapping regions was set to the highest Phred score. Collapsed pairs were aligned using BWA samse v 0.6.1 ( $\mathrm{Li}$ and Durbin, 2009) after stripping adapters. All duplicates were removed with bam-rmdup (https://github.com/mpieva/biohazard-tools) by keeping only the read for each set of duplicates with the highest quality bases.

Sequencing libraries based on high-quality genomic DNAs from $R$. bieti and $P$. nemaeus were constructed with an insert size of $350 \mathrm{bp}$ and sequenced on an Illumina HiSeq 2500 platform using PE 100-150 bp reads. All newly sequenced genomic data generated for this study were deposited on the Short Read Archive (SRA) database under project number: PRJNA616055.

\section{Reads Alignment, Genotype Calling, and Filtering}

A high-quality reference genome is needed for population genomic studies. The published chromosome-level genome of the golden snub-nosed monkey (Wang et al., 2019a) was used as the reference genome here. Reads were aligned to the reference genome with BWA-MEM ( $\mathrm{Li}$ and Durbin, 2009) and SAMtools v.1.3 to generate BAM files ( $\mathrm{Li}$ et al., 2009). Aligned reads were realigned around inserts/deletions (INDELs) using GATK v3.8 indelRealigner (Mckenna et al., 2010) and duplicate reads were marked using Picard v2.10.3 (https://broadinstitute.github.io/picard).

We called single nucleotide polymorphism (SNPs) with GATK v3.8 HaplotypeCaller (Mckenna et al., 2010). Raw SNPs were then filtered for quality and depth using the following criteria: Variants failing the recommended GATK hard filters $(\mathrm{QD}<2.0$ || FS $>60.0 \| \mathrm{MQ}<40.0$ || ReadPosRankSum $<-8.0$ || SB $>=$ -1.0 || DP $<3$ ), low Phred score (QUAL of $<30$ ), missingness above 20\%, allele frequency $<5 \%$ and sites identified within $\mathrm{CpG}$ islands using CpGIScan software (Jian et al., 2017) with default parameter values were excluded. Only biallelic autosomal SNPs 
were analyzed in this study (i.e., triallelic SNPs and SNPs with mapping to the chromosomes $\mathrm{X}$ and $\mathrm{Y}$ were excluded).

\section{Close Kinship Analyses}

Given that the close relationship of samples has the potential to bias the heterozygosity, inbreeding, and genetic load results, so the kinship analyses among the collected genome sequences from the individuals for each species were performed with the Kinship-based Inference for Genome-wide association studies (KING) (Manichaikul et al., 2010) to remove the potential consanguineous individuals. Kinship coefficient was estimated with the "-kinship" command from KING v.2.2.5, which reflects the proportion of SNPs with identical state (IBS0, identity by state zero) between individuals. Negative coefficients indicate unrelated relationships, while positive coefficients indicate genealogy links between individuals. Nonconsanguineous individuals (kinship coefficients $<0$ ) were used in the subsequent analyses (Supplementary Table $\mathbf{1}$ ).

\section{Whole Genome Heterozygosity and Nucleotide Mismatches Analyses}

Whole genome heterozygosity $(\mathrm{He})$ and pairwise nucleotide divergence were computed in 100-kb sliding-window size with no step using variant cell format (VCF) tools (Danecek et al., 2011) and in-house Perl scripts, respectively.

\section{Runs of Homozygosity and Inbreeding Analyses}

Run of homozygosity (ROHs) are contiguous homozygous segments of the genome where the two haplotypes inherited from the parents are identical (Gibson et al., 2006), which can be used to estimate inbreeding level (Keller et al., 2011). Since recombination events interrupt lengthy genome segment, thus long $\mathrm{ROHs}$ (long-ROHs) represent recent inbreeding events (Van Der Valk et al., 2019a). We used the physical length of $\mathrm{ROH}$ as an approximation for genetic length and estimated that the long $\mathrm{ROHs}$ of $1-\mathrm{Mb}$ trace back to $<50$ generations ago $\left(g=100 / 2 * \mathrm{ROH}_{\text {Length}}\right.$, where $g$ is the number of generations and $\mathrm{ROH}_{\text {Length }}$ is the ROHs length in centimorgans) (Thompson, 2013). ROHs were identified for each individual using the "run of homozygosity" function in the program PLINK v1.90 (Purcell et al., 2007). We ran sliding windows of 20 SNPs on the VCF files of all genomes, requiring at least one SNP per $10 \mathrm{~kb}$. In each individual genome, we allowed for the maximum of one heterozygous and 50 missing calls per windows.

The proportion of the genome within ROHs, i.e., genomic inbreeding coefficient $\left(\mathrm{F}_{\mathrm{ROH}}\right)$, was calculated as the total length of $\mathrm{ROH}$ within an individual divided by the length of the genome (Mcquillan et al., 2008).

\section{Genetic Load Analyses}

Deleterious mutations (genetic load) are predicted to disrupt gene function, and therefore expected to substantially reduce the mean fitness of individuals in a species/population (Mattila et al., 2012). To estimate genetic load in the endangered snubnosed monkeys, we used SnpEff v.4.3t (Cingolani et al., 2012) to annotate variant sites (in our multisample VCF) based on the mappings and genome annotation of the golden snubnosed monkey (Wang et al., 2019a) and to identify loss-offunction (LOF), missense, and synonymous mutations. The major homozygous alleles (allele frequency above 0.5 ) in each species and also in at least one of the outgroup species were used to represent the ancestral state. As an indicator of mutational load, for each individual, we counted the number of genes containing one or more homozygous-derived LOF and the total number of homozygous-derived missense mutations divided by the number of synonymous mutations (Fay et al., 2001; Van Der Valk et al., 2020), respectively.

We identified candidate genes with deleterious mutations for each species/population as those satisfying the following criteria: (i) mutations classified as LOF and (ii) mutations being homozygous and derived alleles.

\section{RESULTS AND DISCUSSION}

\section{Data, Sequencing, and SNP Calling}

We analyzed a total of 106 individuals from all five snub-nosed monkey species and two outgroups, one Pygathrix nemaeus and one Macaca mulatta (Supplementary Table 1). Short reads from each individual were aligned to the high-quality chromosomal reference genome of the golden snub-nosed monkey (Wang et al., 2019a). An average mapping rate is $99.14 \%$ (78.73-100\%), and average genomic depth is 12.02 -fold coverage (5.04-35.25-fold coverage) (Supplementary Table 1). The high alignment rate and coverage ensures accurate identification of genetic variations. After stringent quality filtering, we identified a total of 108.28 million high-quality autosomal SNPs in the snub-nosed monkeys and the two outgroups.

Based on the kinship analyses, 44 potential consanguineous individuals (kinship coefficients $>0$ ) were removed, resulting in a total of 62 individuals from all five snub-nosed monkeys used in the present analyses (kinship coefficients $<0$ ). These included 40 individuals from $R$. roxellana (22 from SG, 13 from $\mathrm{QL}$, and 5 from SNJ), $14 R$. bieti, 4 R. strykeri, 2 R. avunculus, and 2 R. brelichi (Supplementary Table 1). After the removal of consanguineous individuals, we identified a total of 98.97 million high-quality autosomal SNPs in the 62 snub-nosed monkeys and the two outgroups.

\section{Genetic Diversity Analyses}

Whole genome heterozygosity $(\mathrm{He})$ in snub-nosed monkeys ranged from 0.034 to $0.069 \%$ (Figure $2 \mathrm{~A}$ ). These estimates are similar to those obtained from other endangered and critically endangered primates, including aye-aye, Eastern lowland gorilla, mountain gorilla, Bornean orangutan, and pileated gibbon (0.051-0.073\%) (Locke et al., 2011; Perry et al., 2012; Carbone et al., 2014; Xue et al., 2015), as well as estimated obtained from carnivores, including Bengal tiger, Amur tiger, white tiger, white lion, and African lion (0.040-0.073\%) (Cho et al., 2013; Dobrynin et al., 2015). These estimates suggest that snub-nosed monkeys possess low genetic diversity, a pattern that may be 

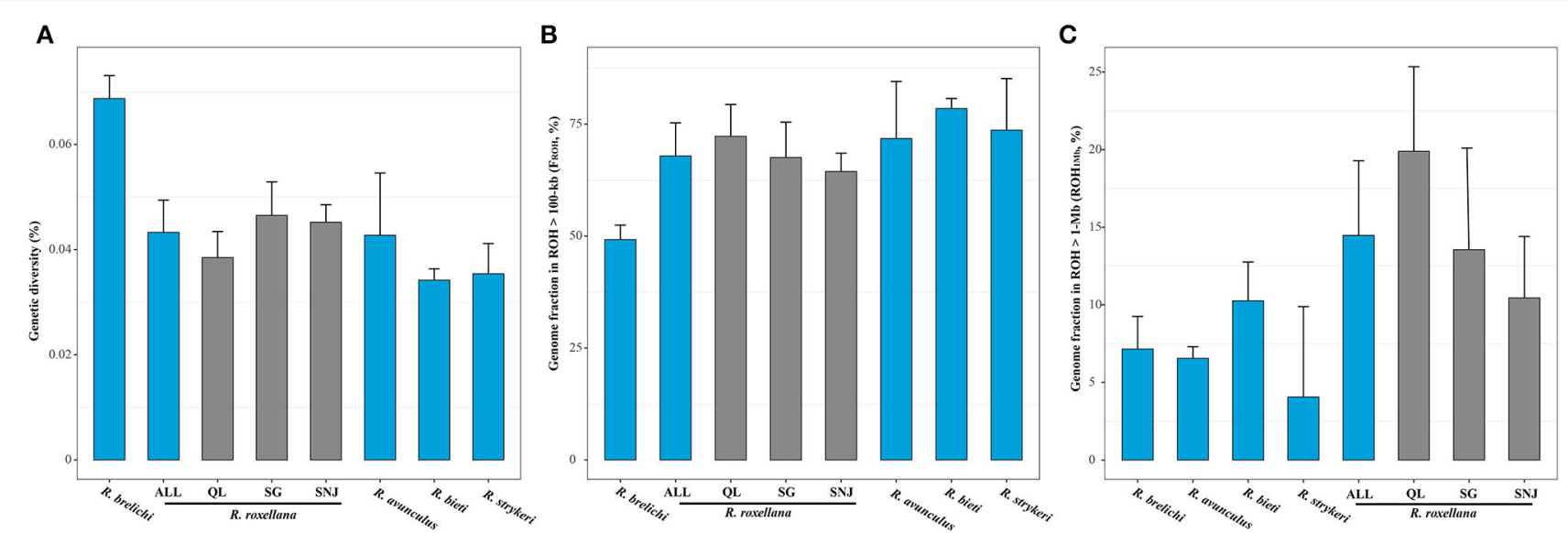

FIGURE 2 | Genetic diversity and inbreeding level in the snub-nosed monkeys. Error bars represent standard deviation (sd). (A) The whole genome heterozygosity $(\mathrm{He})$ of R. brelichi, R. roxellana, R. avunculus, R. bieti, and R. strykeri. Within R. roxellana: ALL, three populations; QL, Qinling population; SG, Sichuan/Gansu population; SNJ, Shennongjia population. (B) Fraction of the genomes in all ROHs (>100 kb) representing the genomic inbreeding coefficient ( $F_{\text {ROH }}$ ). (C) Fraction of genomes in long $\mathrm{ROHs}\left(>1 \mathrm{Mb} ; \mathrm{ROH}_{1 \mathrm{Mb}}\right.$ ) representing the recent inbreeding levels of the snub-nosed monkeys.

related to recent environment change and human activities (Pan and Jablonski, 1987; Li et al., 2002; Zhou et al., 2016).

Contrary to the prevailing notion that smaller populations generally show lower levels of genetic diversity (Leffler et al., 2012; Cho et al., 2013; Prado Martinez et al., 2013; Díezdel-Molino et al., 2018), we found that $R$. brelichi possessed the highest genetic diversity $(\mathrm{He}=0.069 \%$; $p<0.05$, Wilcox test; Figure 2A), despite its population size being lower $(<400$ individuals) than most other species. The unexpectedly high genetic diversity found in $R$. brelichi may be caused by interspecific hybridization (Zhou et al., 2014) or only small population remained from a large population in the recent past (Kolleck et al., 2013). $R$. roxellana $(\mathrm{He}=0.043 \%)$ and $R$. avunculus $(\mathrm{He}=0.042 \%)$ showed the second highest levels of genetic diversity, both higher than $\mathrm{R}$. bieti $(\mathrm{He}=0.034 \%)$ and $R$. strykeri $(\mathrm{He}=0.036 \%)(p<0.05$, Wilcox test). Lower genetic diversity estimates for $R$. bieti and $R$. strykeri are consistent with their small population sizes $(\sim 3,000$ individuals for $R$. bieti and 950 individuals for R. strykeri). The rather higher level of genetic diversity found in $R$. roxellana is consistent with their large population size ( $\sim 22,500$ individuals $)$. We found, however, that although its small population size $(<200$ individuals; the lowest of all five snub-nosed monkey species), $R$. avunculus possesses relatively high genetic diversity, possibly due to ancient introgression or only small population remained from a large population in the recent past, similarly to $R$. brelichi. Intriguingly, the average pairwise nucleotide mismatches in 100$\mathrm{kb}$ windows across the genome was $0.154 \%$ within $R$. avunculus, which is larger than in other snub-nosed monkeys (0.052$0.093 \%)$, suggesting a substantial amount of genetic divergence within the $R$. avunculus population. The two individuals of $R$. avunculus were potentially originated from two substantially diverged populations. These findings are consistent with field surveys that found at least two noncontiguous subpopulations in northern Vietnam (Boonratana and Le, 1998; Zhang et al.,
2016). Our results indicate that these populations are highly divergent in $R$. avunculus, suggesting that they should be managed independently.

As for $R$. brelichi and $R$. avunculus, we found that the smallest population of $R$. roxellana, i.e., SNJ population $(\sim 1,200$ individuals) also possessed relatively higher levels of genetic diversity $(\mathrm{He}=0.044 \%)$ compared with the QL population ( $H e=0.038 \%, \sim 5,500$ individuals, $p=0.0193$, Wilcox test $)$ and even similarly do for the largest population of $R$. roxellana, i.e., SG population ( $\mathrm{He}=0.046 \%$, approximately 16,500 individuals, $p=0.5695$, Wilcox test).

\section{Genomic Inbreeding and Recent Inbreeding Analyses}

We found that genomic inbreeding coefficient $\left(\mathrm{F}_{\mathrm{ROH}}\right)$ of the snub-nosed monkeys to be between 49.37 and $78.86 \%$ (Figure 2B). Compared with other critically endangered or endangered species, the genomic inbreeding levels of the snub-nosed monkeys was higher than in the eastern gorillas $\left(\mathrm{F}_{\mathrm{ROH}}=34-39 \%\right)$ (Xue et al., 2015; Van Der Valk et al., 2019a), vervets $\left(\mathrm{F}_{\mathrm{ROH}}=6-12 \%\right)$ (Van Der Valk et al., 2019a), and pangolins $\left(\mathrm{F}_{\mathrm{ROH}}=12-42 \%\right)$ (Hu et al., 2020). These high levels of inbreeding of the snub-nosed monkeys are consistent with recent dramatic population decline (Zhou et al., 2016).

We found that $R$. brelichi $\left(\mathrm{F}_{\mathrm{ROH}}=49.37 \%\right)$ possessed the lowest level of genomic inbreeding and that $R$. biet $i$ $\left(\mathrm{F}_{\mathrm{ROH}}=78.86 \%\right)$ and $R$. strykeri $\left(\mathrm{F}_{\mathrm{ROH}}=73.43 \%\right)$ have the highest level among the five snub-nosed monkey species $\left(\mathrm{F}_{\mathrm{ROH}}=68.11-78.86 \%\right)(p<0.05$, Wilcox test $)$. Those of R. roxellana $\left(\mathrm{F}_{\mathrm{ROH}}=68.11 \%\right)$ and $R$. avunculus $\left(\mathrm{F}_{\mathrm{ROH}}=68.17 \%\right)$ are in between. As for heterozygosity levels, we found that the SNJ population of $R$. roxellana also possessed the lowest level of genomic inbreeding $\left(\mathrm{F}_{\mathrm{ROH}}=62.83 \%\right)$ compared with the SG $\left(\mathrm{F}_{\mathrm{ROH}}=67.24 \%, p=0.2495\right.$, Wilcox test $)$ and $\mathrm{QL}$ populations $\left(\mathrm{F}_{\mathrm{ROH}}=72.71 \%, p=0.00262\right.$, Wilcox test $)$. Analyses 
of long- $\mathrm{ROHs}$ (>1 Mb; $\mathrm{ROH}_{1 \mathrm{Mb}}$ ) indicated that although there are more individuals of $R$. roxellana than other snub-nosed monkey species, this species generally possessed more longROHs $\left(\mathrm{ROH}_{1 \mathrm{Mb}}, 14.78 \%\right)$ than other species (R. brelichi, 7.41\%; R. bieti, $10.85 \%$; R. strykeri, 3.92\%; and R. avunculus, $7.18 \%)(p<$ 0.05 , Wilcox test), which all have smaller population sizes. Within $R$. roxellana, the $\mathrm{SNJ}$ with the smallest population size possessed the lowest recent inbreeding level $\left(\mathrm{ROH}_{1 \mathrm{Mb}}, 10.19 \%\right)$ compared with the other two populations (SG, 13.01\% and QL, 19.30\%) ( $p$ $<0.05$, Wilcox test) (Figure 2C).

It is generally thought that the smaller the population, the higher the inbreeding level (Keller and Waller, 2002). However, the results demonstrated that $R$. brelichi, $R$. avunculus, and the SNJ population of $R$. roxellana, which represented small populations, show high genetic diversity and low genomic and recent inbreeding. Thus, it seems that a potential mechanism could avoid inbreeding between close relatives, for example, the individual dispersal/transfer between social groups among these species/populations (Qi et al., 2009, 2014; Guo et al., 2010; Chang et al., 2014).

In comparison, $R$. roxellana has a large population size and demonstrates high genetic diversity and low genomic inbreeding, but high recent inbreeding. We speculate that the high recent inbreeding might result from the lower levels of population connectivity and habit utilization $(\sim 0.528-0.587$ $\mathrm{km}^{2}$ /individual) that was shaped by a recent increase in human activity for $R$. roxellana compared with the other snub-nosed monkeys (1-3.763 km²/individual; Supplementary Table 2) (Liu et al., 2015; Meyer et al., 2017; Guo et al., 2020). Thus, $R$. roxellana populations have experienced dozens of recent generations of close inbreeding in spite of their largest population size in the wild compared with other snub-nosed monkeys (Zhou et al., 2016).

\section{Genetic Load Analyses}

High levels of inbreeding can lead to increased homozygosity of recessive deleterious mutations, especially for small and isolated species/populations (Charlesworth and Willis, 2009), which will disrupt gene function or reduce individual fitness. We found that among the snub-nosed monkeys, individuals of $R$. roxellana with the highest recent inbreeding level carried significantly fewer homozygous-derived LOF (homozygous LOF/synonymous, $0.36 \%$ ) than the other snub-nosed monkey species ( $R$. brelichi: homozygous LOF/synonymous, $0.45 \%$; $R$. strykeri: homozygous LOF/synonymous, $0.49 \%$; $R$. avunculus: homozygous LOF/synonymous, $0.49 \%$; and $R$. bieti: homozygous LOF/synonymous, $0.55 \%)$ ( $p<0.001$, Wilcox test) (Figure 3A). A similar pattern was observed when analyzing homozygousderived missense mutations (Figure 3B). This suggests that purging homozygous-derived deleterious mutations is more efficient in $R$. roxellana compared with the other snub-nosed monkeys with smaller population sizes.

Our finding that $R$. roxellana possess high levels of inbreeding and relatively lower levels of mutational load results suggest that inbreeding do not necessarily lead to higher level of mutational load as previously suggested (Reed and Frankham, 2003), which is corroborated by the evidence that there is very low overlapping of homozygous-derived deleterious mutation regions with the long- $\mathrm{ROH}$ regions (4.86 and $12.90 \%$ overlapping between the homozygous-derived LOF and missense mutations with the long-ROHs, respectively), but rather more overlap with the short-ROHs regions (47.18 and 54.99\%, respectively) (Figure 4). The present observation in $R$. roxellana that recent inbreeding did not lead to an excessive accumulation of homozygousderived deleterious mutations was also recently reported in the snow leopard, island fox, and cheetah (Van Der Valk et al., 2019b). Interestingly, although the three populations of $R$. roxellana possessed highly different $\mathrm{ROHs}$ and heterozygosity profiles, we found that their levels of mutational load were remarkably similar (SNJ: homozygous LOF/synonymous, $0.33 \%$; SG: homozygous LOF/synonymous, 0.38\%; QL: homozygous LOF/synonymous, $0.38 \%$ ) ( $p>0.05$, Wilcox test). Altogether, these findings support the idea that mutational load may build up over much longer time frame than inbreeding (Van Der Valk et al., 2019b).

Our findings of a significantly fewer homozygous-derived deleterious mutations in $R$. roxellana than in the other snubnosed monkey species contradict that of a previous study, which identified similar numbers of LOF and derived missense mutations in $R$. roxellana, $R$. bieti, and R. brelichi (Zhou et al., 2016). These differences are likely the results of difference in sample sizes ( $R$. roxellana: 40 in the present study vs. 26 in Zhou et al., 2016; R. bieti: 14 in the present study vs. 8 in Zhou et al., 2016; R. brelichi: 2 in the present study vs. 3 in Zhou et al., 2016) and the use of a high-quality chromosome-level reference genome assembly in the present study.

Many of the genes containing homozygous LOF mutations in the snub-nosed monkey genomes were associated with functions related to immunity (three genes in $R$. roxellana, nine genes in $R$. bieti, eight genes in $R$. strykeri, nine genes in $R$. brelichi, and nine genes in $R$. avunculus, Supplementary Table 3). For example, we found LOF mutations at the coagulation factor II receptor-like 3 gene (F2RL3), which is involved in the recruitment and behavior of immune cells and blood coagulation (Vergnolle et al., 2002; Leger et al., 2006; Gomides et al., 2012; Hossain et al., 2015), segregating in all five species. In addition, more immune genes with LOF mutations were found in the snub-nosed monkey species with the smaller population sizes (i.e., R. bieti, R. strykeri, R. brelichi, and R. avunculus). These include genes such as calmodulin-like protein 6 (CALML6) and lymphocyte-specific protein tyrosine kinase genes $(L C K)$, both of which play a key role in the activation of $T / B$ lymphocytes and the maintenance of balance of the immune system (Tewari et al., 2006; Wang et al., 2019b; Sheng et al., 2020). Altogether, this suggests that inbreeding depression may manifest in the form of lowered immune capability in the snub-nosed monkeys.

\section{CONCLUSION}

Overall, this study provides new insights into the impact of population decline on genomic diversity in a set of highly endangered species, the snub-nosed monkeys 

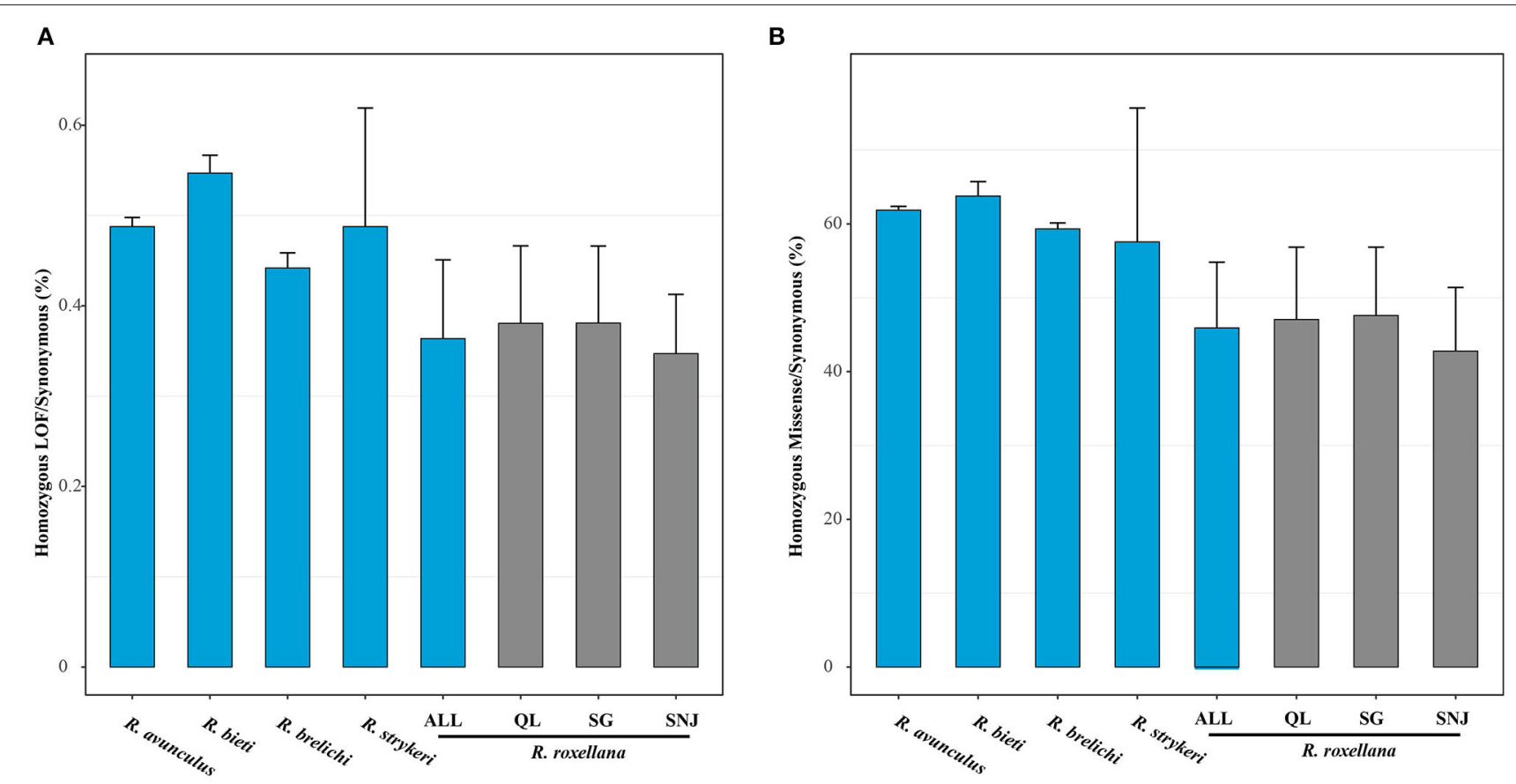

FIGURE 3 | Genetic load of the snub-nosed monkeys. Error bars represent standard deviation (sd). (A) The ratios of the total numbers of homozygous-derived loss of function (LOF) to synonymous mutations of the species/populations. (B) The ratios of the homozygous-derived missense to synonymous mutations.
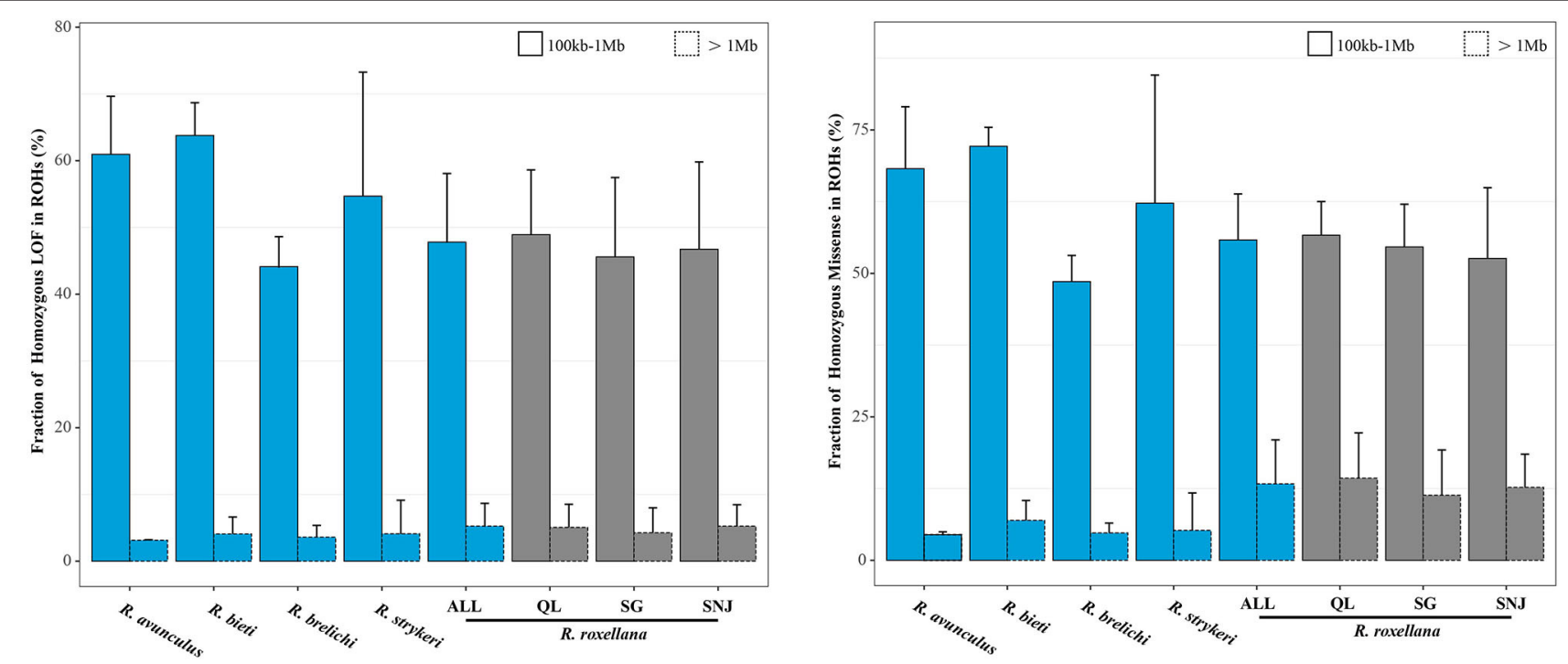

FIGURE 4 | Fractions of homozygous LOF and missense mutations in the ROHs. Error bars represent standard deviation (sd). Bars with solid lines represent short $\mathrm{ROHs}$ (100 kb-1 Mb), and bars with dashed lines represent long $\mathrm{ROHs}(>1 \mathrm{Mb})$.

(genus: Rhinopithecus). Our analyses demonstrated multiple counterintuitive patterns. For example, R. brelichi, R. avunculus, and SNJ population of $R$. roxellana with the small population size showed higher levels of genetic diversity, lower levels of genomic diversity, and recent inbreeding than other snub-nosed monkeys and other populations in $R$. roxellana with the larger population sizes. These findings suggest that, although their census population size is low, they have not yet lost much (if any) of their genetic variability over recent years. However, $R$. roxellana with the largest population size possesses high levels of recent breeding, despite low levels of genomic inbreeding and genetic load as well as high overall genetic diversity. This suggest that, despite its large population size, this species has likely been experiencing recent inbreeding, which has not yet affected its 
overall mutational load, and perhaps has not yet affected its fitness. Analyses of homozygous-derived deleterious mutations identified in all snub-nosed monkeys, however, suggest that these types of mutations are affecting immune, especially in smaller population sizes. This suggests that the long-term consequences of inbreeding may be resulting in an overall reduction of immune capability in the snub-nosed monkeys, which could provide a dramatic effect on their long-term survival prospects.

\section{DATA AVAILABILITY STATEMENT}

The datasets presented in this study can be found in online repositories. The names of the repository/repositories and accession number(s) can be found below: https://www.ncbi.nlm. nih.gov/PRJNA616055.

\section{ETHICS STATEMENT}

The animal study was reviewed and approved by the Committee on Animal Research and Ethics of Yunnan University (No. yuncare20200370).

\section{REFERENCES}

Boonratana, R., and Le, X. C. (1998). Conservation of Tonkin Snub-Nosed Monkeys (Rhinopithecus avunculus) in Vietnam. The Natural History Of The Doucs And Snub-Nosed Monkeys. Singapore: World Scientific.

Carbone, L., Harris, R. A., Gnerre, S., Veeramah, K. R., Lorente-Galdos, B., Huddleston, J., et al. (2014). Gibbon genome and the fast karyotype evolution of small apes. Nature 513, 195-201. doi: 10.1038/nature13679

Chang, Z. F., Luo, M. F., Liu, Z. J., Yang, J. Y., Xiang, Z. F., Li, M., et al. (2012). Human influence on the population decline and loss of genetic diversity in a small and isolated population of Sichuan snub-nosed monkeys (Rhinopithecus roxellana). Genetica 140, 105-114. doi: 10.1007/s10709-012-9662-9

Chang, Z. F., Yang, B. H., Vigilant, L., Liu, Z. J., Ren, B. P., Yang, J. Y., et al. (2014). Evidence of male-biased dispersal in the endangered Sichuan snub-nosed monkey (Rhinopithexus roxellana). Am. J. Primatol. 76, 72-83. doi: 10.1002/ajp.22198

Charlesworth, D., and Willis, J. H. (2009). The genetics of inbreeding depression. Nat. Rev. Genet. 10, 783-796. doi: 10.1038/nrg2664

Cho, Y. S., Hu, L., Hou, H., Lee, H., Xu, J., Kwon, S., et al. (2013). The tiger genome and comparative analysis with lion and snow leopard genomes. Nat. Commun. 4, 2433. doi: $10.1038 /$ ncomms3433

Cingolani, P., Platts, A., Wang Le, L., Coon, M., Nguyen, T., Wang, L., et al. (2012). A program for annotating and predicting the effects of single nucleotide polymorphisms, SnpEff: SNPs in the genome of Drosophila melanogaster strain w1118; iso-2; iso-3. Fly 6, 80-92. doi: 10.4161/fly.19695

Danecek, P., Auton, A., Abecasis, G., Albers, C. A., Banks, E., Depristo, M. A., et al. (2011). The variant call format and VCFtools. Bioinformatics 27, 2156-2158. doi: 10.1093/bioinformatics/btr330

Díez-del-Molino, D., Sánchez-Barreiro, F., Barnes, I., Gilbert, M. T. P., and Dalén, L. (2018). Quantifying temporal genomic erosion in endangered species. Trends Ecol. Evol. 33, 176-185. doi: 10.1016/j.tree.2017.12.002

Dobrynin, P., Liu, S., Tamazian, G., Xiong, Z., Yurchenko, A. A., Krasheninnikova, K., et al. (2015). Genomic legacy of the African cheetah, Acinonyx jubatus. Genome Biol. 16:277. doi: 10.1186/s13059-015-0837-4

Fay, J. C., Wyckoff, G. J., and Wu, C. I. (2001). Positive and negative selection on the human genome. Genetics 158, 1227-1234. doi: 10.1002/gepi.1019

Frankham, R. (2005). Genetics and extinction. Biol. Conserv. 126, 0-140. doi: 10.1016/j.biocon.2005.05.002

\section{AUTHOR CONTRIBUTIONS}

LY designed the study. WK performed the data analyses. WK, $\mathrm{LY}$, and QF wrote the manuscript. XF and QD performed the genomic DNA extraction and preparation of sequencing libraries. WX, CR, TN, LZ, and XY provided the samples. JH, HW, LF, DI, $\mathrm{CR}$, and TN reviewed and revised the manuscript. All authors read and approved the final manuscript.

\section{FUNDING}

This work was supported by a grant from the National Natural Science Foundation of China (No. 31925006), a grant from the Yunnan University's Research Innovation Fund for Graduate Students (2019z050) and the Academic Graduate Students Foundation of Yunnan Province.

\section{SUPPLEMENTARY MATERIAL}

The Supplementary Material for this article can be found online at: https://www.frontiersin.org/articles/10.3389/fgene. 2020.615926/full\#supplementary-material

Geissmann, T., Lwin, N., Aung, S. S., Aung, T. N., Aung, Z. M., Hla, T. H., et al. (2011). A new species of snub-nosed monkey, genus Rhinopithecus Milne-Edwards, 1872 (Primates, Colobinae), from northern Kachin state, northeastern Myanmar. Am. J. Primatol. 73, 96-107. doi: 10.1002/ajp.20894

Gibson, J., Morton, N. E., and Collins, A. (2006). Extended tracts of homozygosity in outbred human populations. Hum. Mol. Genet. 15, 789-795. doi: 10.1093/hmg/ddi493

Gomides, L. F., Duarte, I. D., Ferreira, R. G., Perez, A. C., Francischi, J. N., and Klein, A. (2012). Proteinase-activated receptor-4 plays a major role in the recruitment of neutrophils induced by trypsin or carrageenan during pleurisy in mice. Pharmacology 89, 275-282. doi: 10.1159/000337378

Guo, S. T., Ji, W. H., Li, M., Chang, H. L., and Li, B. G. (2010). The mating system of the Sichuan snub-nosed monkey (Rhinopithecus roxellana). Am. J. Primatol. 72, 25-32. doi: 10.1002/ajp.20747

Guo, Y., Ren, B., Dai, Q., Zhou, J., Paul, A. G., and Zhou, J. (2020). Habitat estimates reveal that there are fewer than 400 Guizhou snub-nosed monkeys, Rhinopithecus brelichi, remaining in the wild. Glob. Ecol. Conserv. 2020:e01181. doi: 10.1016/j.gecco.2020.e01181

Han, D. F. (1982). Mammalian fossils from Tashin country, Guangxi. Vertebr. Palasiatica 2, 58-63.

Hansson, B., and Westerberg, L. (2002). On the correlation between heterozygosity and fitness in natural populations. Mol. Ecol. 11, 2467-2474. doi: 10.1046/j.1365-294X.2002.01644.x

Heller, N. E., and Zavaleta, E. S. (2009). Biodiversity management in the face of climate change: a review of 22 years of recommendations. Biol. Conserv. 142, 14-32. doi: 10.1016/j.biocon.2008.10.006

Hong, Y., Duo, H., Hong, J., Yang, J., Liu, S., Yu, L., et al. (2017). Resequencing and comparison of whole mitochondrial genome to gain insight into the evolutionary status of the Shennongjia golden snub-nosed monkey (SNJ R. roxellana). Ecol. Evol. 7, 4456-4464. doi: 10.1002/ece3.3011

Hossain, M. B., Li, H. Q., Hedmer, M., Tinnerberg, H., and Broberg, K. (2015). Exposure to welding fumes is associated with hypomethylation of the F2RL3 gene: a cardiovascular disease marker. Occup. Environ. Med. 72, 845-851. doi: 10.1136/oemed-2015-102884

Hu, J. Y., Hao, Z. Q., Frantz, L., Wu, S. F., Chen, W., Jiang, Y. F., et al. (2020). Genomic consequences of population decline in critically endangered pangolins and their demographic histories. Natl. Sci. Rev. 7, 798-814. doi: $10.1093 /$ nsr/nwaa031 
Jablonski, N. G. (1998). The response of catarrhine primates to Pleistocene environmental fluctuations in East Asia. Primates 39, 29-37. doi: 10.1007/BF02557741

Jablonski, N. G., and Pan, Y. R. (1988). The evolution and palaeobiogeographic of monkeys in China. Palaeoenviron. East Asia Midtert. 2, 849-867.

Jian, Z., Du, L., Zhang, X., Yue, B., and Fan, Z. (2017). CpGIScan: an ultrafast tool for CpG islands identification from genome sequence. Curr. Bioinform. 12, 181-184. doi: 10.2174/1574893611666160907111325

John, J. S. (2011). Available online at: https://github.com/jstjohn/SeqPrep.

Jump, A. S., Marchant, R., and Penuelas, J. (2009). Environmental change and the option value of genetic diversity. Trends Plant Sci. 14, 51-58. doi: $10.1016 /$ j.tplants.2008.10.002

Keller, L. F., and Waller, D. M. (2002). Inbreeding effects in wild populations. Trends Ecol. Evol. 17, 230-241. doi: 10.1016/S0169-5347(02)02489-8

Keller, M. C., Visscher, P. M., and Goddard, M. E. (2011). Quantification of inbreeding due to distant ancestors and its detection using dense single nucleotide polymorphism data. Genetics 189, 237-249. doi: 10.1534/genetics.111.130922

Kircher, M., Sawyer, S., and Meyer, M. (2012). Double indexing overcomes inaccuracies in multiplex sequencing on the Illumina platform. Nucleic Acids Res. 40:e3. doi: 10.1093/nar/gkr771

Kolleck, J., Yang, M., Zinner, D., and Roos, C. (2013). Genetic diversity in endangered Guizhou snub-nosed monkeys (Rhinopithecus brelichi): contrasting results from microsatellite and mitochondrial DNA data. PLoS ONE 8:e73647. doi: 10.1371/journal.pone.0073647

Kuang, W. M., Ming, C., Li, H. P., Wu, H., Frantz, L., Roos, C., et al. (2019). The origin and population history of the endangered golden snubnosed monkey (Rhinopithecus roxellana). Mol. Biol. Evol. 36, 487-499. doi: 10.1093/molbev/msy220

Leffler, E. M., Bullaughey, K., Matute, D. R., Meyer, W. K., Segurel, L., Venkat, A., et al. (2012). Revisiting an old riddle: what determines genetic diversity levels within species? PLoS Biol. 10:e1001388. doi: 10.1371/journal.pbio.1001388

Leger, A. J., Covic, L., and Kuliopulos, A. (2006). Protease-activated receptors in cardiovascular diseases. Circulation 114, 1070-1077. doi: 10.1161/CIRCULATIONAHA.105.574830

Li, B., Li, M., Li, J., Fan, P., Ni, Q., Lu, J., et al. (2018). The primate extinction crisis in China: immediate challenges and a way forward. Biodivers. Conserv. 27, 3301-3327. doi: 10.1007/s10531-018-1614-y

Li, B., Pan, R., and Oxnard, C. E. (2002). Extinction of snub-nosed monkeys in China during the past 400 years. Int. J. Primatol. 23, 1227-1244. doi: 10.1023/A:1021122819845

Li, H., and Durbin, R. (2009). Fast and accurate short read alignment with Burrows-Wheeler transform. Bioinformatics 25, 1754-1760. doi: 10.1093/bioinformatics/btp324

Li, H., Handsaker, B., Wysoker, A., Fennell, T., Ruan, J., Homer, N., et al. (2009). The sequence alignment/map format and SAMtools. Bioinformatics 25, 2078-2079. doi: 10.1093/bioinformatics/btp352

Li, M., Liu, Z., Gou, J., Ren, B., Pan, R., Su, Y., et al. (2007). Phylogeography and population structure of the golden monkeys (Rhinopithecus roxellana): inferred from mitochondrial DNA sequences. Am. J. Primatol. 69, 1195-1209. doi: 10.1002/ajp.20425

Li, M., Wei, F., Huang, C., Pan, R., and Ruiter, J. D. (2004). Phylogeny of snub-nosed monkeys inferred from mitochondrial DNA, cytochrome B, and 12S rRNA sequences. Int. J. Primatol. 25, 861-873. doi: 10.1023/B:IJOP.0000029126.27618.88

Liedigk, R., Yang, M., Jablonski, N. G., Momberg, F., Geissmann, T., Lwin, N., et al. (2012). Evolutionary history of the odd-nosed monkeys and the phylogenetic position of the newly described Myanmar snub-nosed monkey Rhinopithecus strykeri. PLoS ONE 7:e37418. doi: 10.1371/journal.pone. 0037418

Liu, Z., Liu, G., Roos, C., Wang, Z., Xiang, Z., Zhu, P., et al. (2015). Implications of genetics and current protected areas for conservation of 5 endangered primates in China. Conserv. Biol. 29, 1508-1517. doi: 10.1111/cobi. 12581

Liu, Z., Ren, B., Wei, F., Long, Y., Hao, Y., and Li, M. (2007). Phylogeography and population structure of the Yunnan snub-nosed monkey (Rhinopithecus bieti) inferred from mitochondrial control region DNA sequence analysis. Mol. Ecol. 16, 3334-3349. doi: 10.1111/j.1365-294X.2007.03383.x
Liu, Z., Ren, B., Wu, R., Zhao, L., Hao, Y., Wang, B., et al. (2009). The effect of landscape features on population genetic structure in Yunnan snub-nosed monkeys (Rhinopithecus bieti) implies an anthropogenic genetic discontinuity. Mol. Ecol. 18, 3831-3846. doi: 10.1111/j.1365-294X.2009.04330.x

Locke, D. P., Hillier, L. W., Warren, W. C., Worley, K. C., Nazareth, L. V., Muzny, D. M., et al. (2011). Comparative and demographic analysis of orangutan genomes. Nature 469, 529-533. doi: 10.1038/nature09687

Ma, C., Huang, Z., Zhao, X., Zhang, L., Sun, W., Scott, M. B., et al. (2014). Distribution and conservation status of Rhinopithecus strykeri in China. Primates 55, 377-382. doi: 10.1007/s10329-014-0425-3

Manichaikul, A., Mychaleckyj, J. C., Rich, S. S., Daly, K., Sale, M., and Chen, W. M. (2010). Robust relationship inference in genome-wide association studies. Bioinformatics 26, 2867-2873. doi: 10.1093/bioinformatics/btq559

Mattila, A. L., Duplouy, A., Kirjokangas, M., Lehtonen, R., Rastas, P., and Hanski, I. (2012). High genetic load in an old isolated butterfly population. Proc. Natl. Acad. Sci. U.S.A. 109, E2496-2505. doi: 10.1073/pnas.1205789109

Mckenna, A., Hanna, M., Banks, E., Sivachenko, A., Cibulskis, K., Kernytsky, A., et al. (2010). The Genome Analysis Toolkit: a MapReduce framework for analyzing next-generation DNA sequencing data. Genome Res. 20, 1297-1303. doi: $10.1101 /$ gr.107524.110

Mcquillan, R., Leutenegger, A. L., Abdel-Rahman, R., Franklin, C. S., Pericic, M., Barac-Lauc, L., et al. (2008). Runs of homozygosity in European populations. Am. J. Hum. Genet. 83, 359-372. doi: 10.1016/j.ajhg.2008.08.007

Meyer, D., Momberg, F., Matauschek, C., Oswald, P., Lwin, N., Aung, S., et al. (2017). Conservation Status of the Myanmar or Black Snub-Nosed Monkey Rhinopithecus strykeri. Yangon: Fauna \& Flora International; Göttingen: Institute of Eastern-Himalaya Biodiversity Research, Dali, China; and German Primate Center.

Meyer, M., and Kircher, M. (2010). Illumina sequencing library preparation for highly multiplexed target capture and sequencing. Cold Spring Harb. Protoc. 2010:pdb.prot5448. doi: 10.1101/pdb.prot5448

Nadler, T. (2018). “Tonkin snub-nosed monkey" in Schwitzer, C., Mittermeier, R. A., Ryalnds, A. B., Chiozza, F., Williamson, E. A., Byler, D., Wich, S., Humle, T., Johnson, C., Mynott, H., and McCabe, G., eds. IUCN SSC Primate Specialist Group. International Primatological Society, Global Wildlife Conservation and Bristol Zoological Society. Manipal: Manipal Universal Press.

Nuchel, J., Bocher, P. K., Xiao, W., Zhu, A. X., and Svenning, J. C. (2018). Snub-nosed monkeys (Rhinopithecus): potential distribution and its implication for conservation. Biodivers. Conserv. 27, 1517-1538. doi: 10.1007/s10531-018-1507-0

Pan, Y. R., and Jablonski, N. G. (1987). The age and geographical distribution of fossil cercopithecids in China. Hum. Evol. 2, 59-69. doi: 10.1007/BF02436531

Perry, G. H., Reeves, D., Melsted, P., Ratan, A., Miller, W., Michelini, K., et al. (2012). A genome sequence resource for the aye-aye (Daubentonia madagascariensis), a nocturnal lemur from Madagascar. Genome Biol. Evol. 4, 126-135. doi: 10.1093/gbe/evr132

Prado Martinez, J., Sudmant, P. H., Kidd, J. M., Li, H., Kelley, J. L., Lorente Galdos, B., et al. (2013). Great ape genetic diversity and population history. Nature 499, 471-475. doi: 10.1038/nature12228

Purcell, S., Neale, B., Todd-Brown, K., Thomas, L., Ferreira, M. A., Bender, D., et al. (2007). PLINK: a tool set for whole-genome association and populationbased linkage analyses. Am. J. Hum. Genet. 81, 559-575. doi: 10.1086/ 519795

Qi, X. G., Garber, P. A., Ji, W. H., Huang, Z. P., Huang, K., Zhang, P., et al. (2014) Satellite telemetry and social modeling offer new insights into the origin of primate multilevel societies. Nat. Commun. 5:5296. doi: 10.1038/ncomms6296

Qi, X. G., Li, B. G., Garber, P. A., Ji, W. H., and Watanabe, K. (2009). Social dynamics of the golden snub-nosed monkey (Rhinopithecus roxellana): female transfer and one-male unit succession. Am. J. Primatol. 71, 670-679. doi: 10.1002/ajp.20702

Quan, G., and Xie, J. (2002). Research on the Golden Monkeys. Beijing: Science and Education Publishing House, 79-92.

Reed, D. H., and Frankham, R. (2003). Correlation between fitness and genetic diversity. Conserv. Biol. 17, 230-237. doi: 10.1046/j.1523-1739.2003.01236.x

Ren, G. P., Yang, Y., He, X. D., Li, G. S., Gao, Y., Huang, Z. P., et al. (2017). Habitat evaluation and conservation framework of the newly discovered and critically endangered black snub-nosed monkey. Biol. Conserv. 209, 273-279. doi: 10.1016/j.biocon.2017.02.029 
Sheng, C., Wang, Z., Yao, C., Chen, H. M., Kan, G., Wang, D., et al. (2020). CALML6 controls TAK1 ubiquitination and confers protection against acute inflammation. J. Immunol. 204, 3008-3018. doi: 10.4049/jimmunol.1901042

Tewari, K., Walent, J., Svaren, J., Zamoyska, R., and Suresh, M. (2006). Differential requirement for Lck during primary and memory CD8+ T cell responses. Proc. Natl. Acad. Sci. U.S.A. 103, 16388-16393. doi: 10.1073/pnas.0602565103

Thompson, E. A. (2013). Identity by descent: variation in Meiosis, across genomes, and in populations. Genetics 194, 301-326. doi: 10.1534/genetics.112.148825

Van Der Valk, T., Díez-del-Molino, D., Marques-Bonet, T., Guschanski, K., and Dalen, L. (2019a). Historical genomes reveal the genomic consequences of recent population decline in eastern gorillas. Curr. Biol. 29, 165-170 e166. doi: 10.1016/j.cub.2018.11.055

Van Der Valk, T., Gonda, C. M., Silegowa, H., Almanza, S., Sifuentes-Romero, I., Hart, T. B., et al. (2020). The genome of the endangered dryas monkey provides new insights into the evolutionary history of the vervets. Mol. Biol. Evol. 37, 183-194. doi: 10.1093/molbev/msz213

Van Der Valk, T., Manuel, M. D., Marques-Bonet, T., and Guschanski, K. (2019b). Estimates of genetic load in small populations suggest extensive purging of deleterious alleles. bioRxiv [Preprint]. doi: 10.1101/696831

Vergnolle, N., Derian, C. K., D’andrea, M. R., Steinhoff, M., and AndradeGordon, P. (2002). Characterization of thrombin-induced leukocyte rolling and adherence: a potential proinflammatory role for proteinase-activated receptor4. J. Immunol. 169, 1467-1473. doi: 10.4049/jimmunol.169.3.1467

Wang, L., Wu, J., Liu, X., Di, D., Liang, Y., Feng, Y., et al. (2019a). A highquality genome assembly for the endangered golden snub-nosed monkey (Rhinopithecus roxellana). Gigascience 8:98. doi: 10.1093/gigascience/giz098

Wang, Z., Sheng, C., Yao, C., Chen, H., Wang, D., and Chen, S. (2019b). The EF-Hand protein CALML6 suppresses antiviral innate immunity by impairing IRF3 dimerization. Cell Rep. 26, 1273-1285.e1275. doi: 10.1016/j.celrep.2019.01.030

Xue, Y., Prado-Martinez, J., Sudmant, P. H., Narasimhan, V., Ayub, Q., Szpak, M., et al. (2015). Mountain gorilla genomes reveal the impact of long-term population decline and inbreeding. Science 348, 242-245. doi: 10.1126/science.aaa3952

Yang, M., Yang, Y., Cui, D., Fickenscher, G., Zinner, D., Roos, C., et al. (2012). Population genetic structure of Guizhou snub-nosed monkeys (Rhinopithecus brelichi) as inferred from mitochondrial control region sequences, and comparison with R. roxellana and R. bieti. Am. J. Phys. Anthropol. 147, 1-10. doi: 10.1002/ajpa.21618
Yang, Y., Ren, G., Li, W., Huang, Z., Lin, A. K., Garber, P. A., et al. (2019). Identifying transboundary conservation priorities in a biodiversity hotspot of China and Myanmar: Implications for data poor mountainous regions. Glob. Ecol. Conserv. 20:e00732. doi: 10.1016/j.gecco.2019.e00732

Yu, L., Wang, G. D., Ruan, J., Chen, Y. B., Yang, C. P., Cao, X., et al. (2016). Genomic analysis of snub-nosed monkeys (Rhinopithecus) identifies genes and processes related to high-altitude adaptation. Nat. Genet. 48, 947-952. doi: 10.1038/ng.3615

Zhang, P., Hu, K., Yang, B., and Yang, D. (2016). Snub-nosed monkeys (Rhinopithecus spp.): conservation challenges in the face of environmental uncertainty. Sci. Bull 61, 345-348. doi: 10.1007/s11434-016-1008-Z

Zhang, S. J., Liu, C. J., Yu, P., Zhong, X., Chen, J. Y., Yang, X., et al. (2014). Evolutionary interrogation of human biology in well-annotated genomic framework of rhesus macaque. Mol. Biol. Evol. 31, 1309-1324. doi: $10.1093 / \mathrm{molbev} / \mathrm{msu} 084$

Zhang, Y., and Ryder, O. A. (1997). Mitochondrial DNA sequence evolution and conservation relevance of snub-nosed langurs. Yi Chuan Xue Bao 24, 116-121.

Zhao, X., Ren, B., Li, D., Xiang, Z., Garber, P. A., and Li, M. (2019). Effects of habitat fragmentation and human disturbance on the population dynamics of the Yunnan snub-nosed monkey from 1994 to 2016. PeerJ. 7:e6633. doi: $10.7717 /$ peerj. 6633

Zhou, X., Meng, X., Liu, Z., Chang, J., Wang, B., Li, M., et al. (2016). Population genomics reveals low genetic diversity and adaptation to hypoxia in snub-nosed monkeys. Mol. Biol. Evol. 33, 2670-2681. doi: 10.1093/molbev/msw150

Zhou, X., Wang, B., Pan, Q., Zhang, J., Kumar, S., Sun, X., et al. (2014). Wholegenome sequencing of the snub-nosed monkey provides insights into folivory and evolutionary history. Nat. Genet. 46, 1303-1310. doi: 10.1038/ng.3137

Conflict of Interest: The authors declare that the research was conducted in the absence of any commercial or financial relationships that could be construed as a potential conflict of interest.

Copyright (C) 2020 Kuang, Hu, Wu, Fen, Dai, Fu, Xiao, Frantz, Roos, Nadler, Irwin, Zhou, Yang and Yu. This is an open-access article distributed under the terms of the Creative Commons Attribution License (CC BY). The use, distribution or reproduction in other forums is permitted, provided the original author $(s)$ and the copyright owner(s) are credited and that the original publication in this journal is cited, in accordance with accepted academic practice. No use, distribution or reproduction is permitted which does not comply with these terms. 